\title{
POLÍTICAS SOCIALES Y ORGANIZACIONES POPULARES EN ARGENTINA (2003-2011): mediación social y movilización política en los barrios periféricos de Buenos Aires
}

\section{POLÍTICAS SOCIAIS E ORGANIZAÇÕES POPULARES NA ARGENTINA (2003-2011): mediação social e mobilização política nos bairros periféricos de Buenos Aires}

\author{
Arnaud Trenta*
}

\begin{abstract}
El artículo se inscribe en los debates en torno a las rupturas y continuidades entre los gobiernos nacionales argentinos de las últimas décadas a partir del análisis de las políticas sociales focalizadas de lucha contra la pobreza. La investigación examina particularmente las relaciones entre las organizaciones sociales y el Estado durante los dos primeros gobiernos kirchneristas (2003-2011) y se focaliza en la ejecución de un programa de inclusión social denominado "Ingreso Social con Trabajo", que apunta a la creación de cooperativas de trabajo en barrios carenciados. Los resultados de la encuesta empírica exhiben cierta continuidad en el diseño y la implementación de las políticas sociales entre los años 1990 y 2000 a través del modelo de transferencias condicionadas de ingreso. De igual manera, ilustra una reconfiguración de las relaciones entre las clases populares y el Estado a través de la alianza política entre el gobierno nacional y las organizaciones sociales.
\end{abstract}

PALABRAS-CLAVES: Políticas sociales. Organizaciones sociales. Clases populares. Kirchnerismo.Argentina.

Este artigo se inscreve nos debates sobre as rupturas e continuidades entre os governos nacionais argentinos das últimas décadas a partir da análise das políticas sociais focalizadas de luta contra a pobreza. A pesquisa examina particularmente as relações entre as organizações sociais e o Estado durante os dois primeiros governos kirchneristas (2003-2011) e focaliza a execução de um programa de inclusão social denominado "Renda social com trabalho", que aponta para a criação de cooperativas de trabalho em bairros carentes. Os resultados da enquete empírica revelam certa continuidade das políticas sociais entre os anos 1990 e 2000 por meio do modelo de transferências condicionadas de renda, manifestada tanto em seu delineamento como nas práticas de execução, que outorgam um poder discricionário aos intermediários. Do mesmo modo, ilustra uma reconfiguração das relações entre as classes populares e o Estado por meio de aliança política entre o governo nacional e as organizações sociais.

Palavras-CHAvE: Políticas sociais. Organizações sociais. Classes populares. Kirchnerismo. Argentina.

\section{INTRODUCCIÓN}

Junto con los gobiernos de Lula en Brasil, de Evo Morales en Bolivia y de Hugo Chávez en Venezuela, la Argentina de los Kirchner ha jugado un rol preponderante en la reconfiguración política e ideológica de América Latina a principios del año 2000. La emergencia de nuevos liderazgos y de gobiernos preocupados por la cuestión social signó el fin del famoso "Consenso de Washington", cuyo proyecto neoliberal aspiraba a reducir las funciones del Estado, la privatización y la desregulación de la economía nacional, al igual que la apertura al mercado mundial (Williamson, 1990). El ac-

* Consejo Nacional de Investigaciones Científicas y Técnicas (CONICET). Instituto de Ciencias Humanas, Sociales y Ambientales (INCIHUSA-CCT).

Ruiz Leal s/n, 5500. Mendoza - Argentina. atrenta@mendoza-conicet.gob.ar ceso al poder de aquellos dirigentes se manifestó - con matices según los contextos nacionales -, en la rehabilitación del rol del Estado como actor central de la regulación económica y social, y en varias reformas que apuntaban a la reducción de la pobreza y la inclusión de los sectores marginales.

A través de este Estado redimensionado, que contó con un crecimiento económico fuerte, la pareja Kirchner pudo llevar a cabo, en Argentina, una serie de políticas sociales en los campos del trabajo, de la educación, de la salud y de la asistencia, cuyos resultados generan controversias en los ámbitos académicos, políticos y mediáticos en torno a si resultaron eficaces para reducir la desigualdad (Andrenacci; Falappa, 2008; Coraggio, 2011; Cortés; Kessler, 2013; Lo Vuolo, 2010; Kessler, 2014; Zarazaga, 2014). Una de las principales pre- 
guntas en torno a la década kirchnerista planteada en los medios académicos es saber en qué medida las políticas públicas implementadas constituyen una ruptura con la década anterior, caracterizada por la reducción de la protección social, la desregulación de la economía y el crecimiento de las desigualdades. Si la ruptura con el neoliberalismo de los años 90 es evidente en el registro discursivo, resulta más complejo analizar los cambios a nivel de los programas institucionales y las prácticas de los actores en la puesta en marcha de las políticas sociales impulsadas por los gobiernos de Néstor y Cristina Kirchner. Por ello, el artículo se interroga sobre los cambios y continuidades en las políticas sociales vinculadas al desempleo y la pobreza durante las últimas décadas, tomando como terreno de investigación un distrito del conurbano bonaerense.

El objetivo principal es analizar las relaciones entre el Estado y las organizaciones sociales en el marco de políticas de inclusión que se focalizan en los barrios populares. El análisis se inscribe en el campo de los estudios sobre las reconfiguraciones del Estado social en el contexto de debilitamiento de la sociedad salarial y de crisis del Estado de Bienestar (Castel, 1995; Esping-Andersen, 1990; Merklen, 2009) que se manifiesta a partir de los años 70 en las sociedades europeas, norऽ t teamericanas y latinoamericanas a través de đ la reducción del perímetro de intervención del Estado y el auge de las organizaciones de ganizaciones sociales frente al retorno de la cuestión social. Bajo estos nuevos paradigmas, las políticas sociales son comprendidas como una configuración de relaciones complejas que mixturan una diversidad de organizaciones públicas y privadas dentro de las cuales las institucionales subnacionales y las organizaciones sociales juegan un rol fundamental en la definición e implementación de políticas locales, particularmente en los intersticios dejados por las medidas nacionales (Brodiez-Dolino, 2013).

En Argentina, durante los años 80-90, los gobiernos como las organizaciones internacionales sostuvieron e incentivaron el desarrollo de las llamadas ONG, o "tercer sector" (Roitter, González Bombal, 2000; Thompson, 1995), con el objetivo de fomentar intermediarios locales para la implementación de las políticas focalizadas de "lucha contra la pobreza” (Prévôt-Schapira, 1996). Este enfoque, más técnico que militante, fue resistido desde los años 2000 a partir del cuestionamiento al modelo neoliberal y de los crecientes bolsones de pobreza. Luego de la crisis de 2001, un conjunto de organizaciones sociales surgidas al calor de la protesta social han mantenido una intensa actividad en los barrios populares, mayoritariamente en relación con las políticas sociales que brindan una asistencia material o monetaria a individuos en situación de vulnerabilidad y (o) implementan servicios y bienes colectivos en territorios relegados (Pérez, Natalucci, 2012; Quirós, 2011; Vommaro, 2017). Lejos de resumirse a una lógica clientelista (Vommaro; Combes, 2016), esta diversidad de organizaciones conforma redes de solidaridad en los territorios populares y participa de la puesta en marcha de las políticas sociales.

Estas relaciones entre el Estado y las organizaciones sociales, en el marco de las políticas de inclusión, sugieren una serie de interrogantes sobre el diseño, la implementación y los usos de las políticas sociales en territorios específicos: ¿Cómo se articulan las distintas escalas del Estado y qué vínculo tienen con las organizaciones implantadas en los territorios populares? ¿Qué autonomía tienen las organizaciones sociales frente a las instituciones políticas que financian los programas sociales? ¿Quiénes deciden, y con qué criterios, la elección de los beneficiarios de 
las políticas sociales? ¿Cuáles son los usos de las políticas sociales a nivel territorial? ¿Cuáles son las prácticas asociativas y las formas de participación en los espacios públicos locales?

En vistas a responder tales preguntas, el examen se basa en la actividad social y política de la organización social llamada Movimiento Evita y se focaliza en su rol en la definición e implementación del programa "Ingreso Social con Trabajo". Este programa, lanzado en 2009, depende de la política pública "Argentina Trabaja" del Ministerio de Desarrollo Social de la Nación y consiste en sustentar la creación de cooperativas en territorios populares que agrupan los trabajadores desocupados más alejados del mercado. La organización Movimiento Evita como la política social "Argentina trabaja" ocuparon un lugar central en la acción gubernamental de los Kirchner, lo que permite movilizar distintas escalas de análisis desde lo local y hacía lo nacional.

El trabajo de campo se realizó entre 2009 y 2011, en una ciudad del primer cordón del conurbano bonaerense, donde una organización del Movimiento Evita administraba varias cooperativas. El enfoque anclado en lo local permitió observar la articulación de las políticas públicas diseñadas en distintos niveles estatales, las prácticas de mediación de las organizaciones sociales a nivel territorial $\mathrm{y}$ los usos que los beneficiarios le otorgan al financiamiento público. Para dar cuenta de las representaciones y prácticas que los actores locales desarrollan en el marco de esta política social, se utilizó el método etnográfico, a partir de la realización de observaciones en el territorio extendidas en el tiempo y de 15 entrevistas en profundidad. ${ }^{1}$ A ello se agregó información proveniente de las administraciones públicas $\mathrm{y}$ de la prensa provincial y nacional. ${ }^{1}$ Por un compromiso con los entrevistados, se ha omitido
sus nombres en el presente artículo.
La primera parte del artículo expone el contexto histórico en el cual se inscriben las políticas sociales y las prácticas de los actores, a partir de la literatura existente. La segunda parte analiza la génesis de la organización local del Movimiento Evita y las formas de trabajo y empleo al interior de las cooperativas. La tercera parte se focaliza en el manejo de los recursos institucionales por parte de los referentes del Movimiento Evita para constituir una red territorial de militancia y generar movilizaciones políticas a la escala local y nacional.

\section{DEL MOVIMIENTO DE TRABAJA- DORES DESOCUPADOS AL MOVI- MIENTO KIRCHNERISTA}

\section{El Movimiento de Trabajadores Desocupados}

A principios de los años 2000, tuvo lugar una reconfiguración de las relaciones entre el Estado y las organizaciones sociales a partir del debilitamiento de los sindicatos tradicionales y el auge de las organizaciones territoriales. Durante la década del 90 y bajo el gobierno de Carlos Menem, las organizaciones sindicales no opusieron una fuerte resistencia a las reformas estructurales de la economía (Murillo, 2005); por ello, las organizaciones de base que conformaron el movimiento de trabajadores desocupados fueron las que encarnaron la revuelta popular en contra del orden neoliberal y manifestaron la importancia de la matriz territorial en las movilizaciones populares (Kessler; Svampa; González Bombal, 2010). El movimiento de trabajadores desocupados tuvo un doble origen: por un lado, se vinculó con los levantamientos populares que tuvieron lugar en provincias del interior, como Santiago del Estero en 1993 y Neuquén en 1996, donde los trabajadores desocupados reclamaron el pago de los salarios o la creación de empleos ante las administraciones provinciales. Durante estas movilizaciones, surgió una nueva modalidad en el repertorio de acción colectiva de los sectores populares, defi- 
nida por la afirmación de la identidad "piquetera”, el corte de rutas como modo de acción, la asamblea como forma de organización y el trabajo como tipo de demandas (Delamata; Armesto, 2005; Svampa; Pereyra, 2003).

Por otro lado, el autodefinido movimiento piquetero se conformó a partir de las organizaciones sociales radicadas desde los años 80 en los territorios pauperizados del conurbano bonaerense, que importaron la acción colectiva piquetera al centro neurálgico del país y permitieron desarrollar el movimiento de trabajadores desocupados a escala nacional. Estas organizaciones adicionaron al flamante movimiento social sus propios modelos de militancia, íntimamente ligados al trabajo en los barrios, y orientaron las demandas hacia planes sociales (Merklen, 2009). Muy heterogéneo en su composición, el movimiento piquetero desarrolló tres grandes orientaciones políticas distintas: una orientación sindical que favorece la negociación y la institucionalización; una orientación partidaria ligada a los partidos de izquierda y la competencia electoral; y una orientación autonomista que prioriza el anclaje territorial y la confrontación con los poderes públicos (Svampa; Pereyra, 2003).

Las respuestas del gobierno de Menem ante el estrepitoso aumento del subempleo y desempleo, lo cual trepó como producto de la స్ crisis del Tequila a un $18 \%$, y las consecuen$\stackrel{\mathbb{D}}{\mathrm{D}}$ tes movilizaciones que pusieron en jaque la gobernabilidad, se dieron a través del plan "Trabajar", lanzado con ayuda del Banco Mundial en 1996. En principio, este plan consistía en otorgar un módico salario mensual ${ }^{2}$ por un lapso de seis meses a los desempleados que no percibían ninguna indemnización, a cambio de la realización de un trabajo comunitario. De acuerdo a la literatura existente, este plan se caracterizó por una ambigüedad entre seguro de desempleo, asistencia pública y clientelismo político (Svampa; Pereyra, 2003). Los recursos financieros seguían un circuito descendente

200 pesos por mes al inicio, es decir, la mitad de la canasta familiar básica. que se puede sintetizar de la siguiente manera: el gobierno nacional decidía el reparto de recursos entre diferentes provincias; los gobiernos de provincias determinaban las municipalidades concernientes y establecían las ayudas asignadas; los intendentes recibían finalmente las sumas acordadas para los diferentes individuos que estiman ser los beneficiarios. La selección de los beneficiarios se realizaba en las escalas más bajas de la administración. El poder discrecional de los dirigentes políticos y la cantidad limitada de planes sociales ${ }^{3}$ tuvieron como efecto la consolidación de las redes clientelares ya presentes en barrios carenciados (Auyero, 2001; Levitsky, 2005), pero, a la vez, reforzaron las organizaciones piqueteras, que optaban por una relación conflictiva con los dirigentes políticos y reclutaban nuevos miembros que querían obtener los beneficios del plan "Trabajar”. Al agrupar los subsidios de sus miembros, estas organizaciones se erigían localmente en interlocutoras ineludibles de los poderes públicos. El número de cortes de ruta pasó así de 100 en 1997 a 500 en 2000 y 1400 en 2001 (Lodola, 2005).

Luego de la crisis de 2001, la tasa de pobreza alcanzó al 42,3\% de los hogares y 54,3\% de la población (Rodríguez Enríquez, Reyes, 2006). El crecimiento de la pobreza se tradujo en un aumento del número de beneficiarios de los planes sociales, que pasó de 140.000 en 1997 a 1.300 .000 en octubre de 2002 (Svampa; Pereyra, 2006), con la puesta en marcha del programa "Jefes y Jefas de hogares desocupados" (JJHD), que cubría una mayor fracción de población y conservaba el mismo circuito de financiamiento. Al igual que las políticas de transferencias condicionadas de ingreso que se difundieron en la región latinoamericana a partir de las primeras experiencias mexicanas y brasileñas (Merrien, 2014), el programa JJHD agregó como condicionalidades la escolarización y la vacunación de los niños, lo que puede fue de 130 millones de pesos, lo que permitía cubrir alrededor del 20\% de los desocupados (Lodola, 2005). 
ser visto como una forma de patronazgo hacia los sectores populares y de moralización de los pobres (Ceballos, Lautier, 2013; Lautier, 2013).

\section{El Movimiento Kirchnerista}

Hacia fines de 2002, las movilizaciones de trabajadores desocupados y otras organizaciones surgidas al calor de la crisis como las asambleas barriales ya mostraban disociaciones y desacuerdos que permiten observar los límites en torno a la unificación de la protesta social. Su desarticulación se acompaña de una creciente demanda de "normalización institucional" por parte de varios sectores sociales, la cual se manifiesta durante las elecciones de abril 2003 con la reafirmación del dominio político de los partidos tradicionales. Con solo el 22,04\% de los votos y gracias a la renuncia de Carlos Menem al ballotage, Néstor Kirchner accede a la presidencia de la República con una legitimidad débil, producto de su escaso margen de sufragios. Sus primeras medidas a favor de los Derechos Humanos le permitieron reactivar un movimiento social clave en el periodo democrático y ganar el apoyo de numerosos intelectuales y organizaciones civiles. De esta manera, Kirchner operó también a favor de un desplazamiento de la conflictividad hacia el problema de los Derechos Humanos que tiende a ocultar la cuestión social todavía vigente.

Frente a las organizaciones piqueteras, Néstor Kirchner actuó de manera ambigua y buscó controlar la protesta social atendiendo a distintas tácticas. Por un lado, el gobierno ejerció una represión en contra de las organizaciones autonomistas o ligadas a partidos de izquierda, que se tradujo en miles de apresados (Svampa, 2008). Esta represión policial y judicial se vinculó con una campaña mediática de deslegitimación de los piqueteros, orquestada tanto por el gobierno como por los grandes medios de comunicación. Por otro lado, el gobierno llevó adelante una cooptación de las agrupaciones que tenían una mayor orientaci- ón sindical, la cual desembocó en la formación de un bloque de organizaciones populares apoyando la acción del nuevo jefe de Estado. Esta cooptación en el seno del gobierno se concretizó particularmente en la participación de esas organizaciones en la puesta en marcha de las políticas sociales en los territorios pauperizados y en la vinculación de sus cuadros en la administración pública nacional y provincial (Merklen, 2006; Perelmiter, 2012).

Entre 2003 y 2005, mientras las organizaciones piqueteras autonomistas o izquierdistas seguían enfrentando al Estado y pidiendo planes sociales, muchas otras de orientación sindical respondieron al llamado de Néstor Kirchner de incorporarse a la acción gubernamental y emprendieron la conformación de un movimiento social kirchnerista. Este cambio en las relaciones entre el Estado y las organizaciones populares territoriales se manifestó también a nivel identitário, ya que las agrupaciones cooptadas dejaron de referirse a la identidad piquetera y a la resistencia característica del periodo neoliberal para proyectarse en el nuevo ciclo político iniciado por Néstor Kirchner, que retomó la cultura militante de los años 70 y la tradición nacional-popular del peronismo (Perez; Natalucci, 2012).

\section{El Movimiento Evita}

El Movimiento Evita se constituyó, en 2005, en el marco de este proceso, gracias al reagrupamiento de numerosas organizaciones sociales de orientación sindical. Su trayectoria está asociada a la de su máximo referente, Emilio Pérsico, quien participó, desde 2003, en la constitución de una alianza con el gobierno nacional y en la coordinación de las organizaciones que conformaron el espacio militante kirchnerista. Consignatario de los textos emblemáticos del proyecto de unificación y canalización del movimiento social, ${ }^{4}$ Pérsico fue zaciones Populares", y luego del "Frente Patria para Todos" 
el principal instigador de un reagrupamiento de distintas organizaciones sociales que dio luz, en 2005, a la fundación del Movimiento Evita, que se caracteriza por valorar la figura del militante. Opuesta a la figura del "puntero" ${ }^{5}$ que simboliza las prácticas clientelares y la usurpación de los recursos públicos, la figura del militante está definida a partir de "un compromiso con una organización cuyo objetivo es construir un proyecto político que pueda modificar el orden social instituido total o parcialmente" (Natalucci, 2012, p. 45). Desde esta perspectiva, que se aproxima a la tradición nacional-popular, la finalidad de la militancia no es garantizar la autonomía de las organizaciones sociales frente al poder político, sino vincularlas al poder para participar en la conformación de un nuevo orden sociopolítico.

La identificación con Néstor y Cristina Kirchner y el proyecto político que lideran está presente en las instancias nacionales y locales del Movimiento Evita. En la organización local estudiada, los responsables han vivido, en carne propia, los procesos de pauperización durante los años 80 y 90, y los gobiernos kirchneristas representan, para ellos, una verdadera esperanza de cambio social, al buscar poner fin a un complejo sistema de desigualdades. La trayectoria de la referente local del Movimiento Evita ilustra este cam亏े bio de perspectiva en relación a los objetivos ๖ y razones de su militancia. Nació en la villa 31 de Retiro y creció en el barrio Ejército de

- da lugar a las siguientes declaraciones: "La Hora de los Pue- blos"; "Por la recuperación del Trabajo y la Justicia Social.

흐 Fuerza Compañero. Presidente Néstor Kirchner”; "Declara-

శึ ción Política del Frente de Organizaciones Populares"; "Diez

స puntos para la unidad de las fuerzas populares".

๘ ${ }^{5}$ La palabra puntero tiene una connotación peyorativa y

denomina un referente barrial que "trabaja" para un políti-

co al nivel territorial. Su propio hogar sirve usualmente de

base a su organización sociopolítica que realiza la media-

ción entre el vecindario y la política (reclamos de vecinos,

distribución de bienes de primera necesidad, movilizaci-

گ ón a favor del "patrón" político, etc.). digna y legal. Después de veinte años de movilización dedicados a los problemas de subsistencia en situaciones críticas, empezó, a partir del 2003, a militar por el mejoramiento del trabajo, de la educación, de la salud, etc. Esta referente local describe la llegada al poder de los Kirchner como una nueva etapa de la democracia, que pone fin a la resistencia del periodo neoliberal:

Con todo el proceso del neoliberalismo, lo que nos
llevó fue a cada uno refugiarnos en su hogar para
sostenerlo. Porque había desocupación, había mu-
chas crisis... Toda la época del neoliberalismo fue
una época mucho más dura porque cerraban las fab-
ricas, había mucha desesperación... A raíz de esta
nueva etapa de la democracia, que empezó en 2003 ,
hubo como más perspectivas, como una esperanza
nueva de que podemos juntarnos y volver a hacer
militancia... es decir cambiar la realidad de mucha
gente, no solamente por mí, sino de los que están
peor. Pasar de la resistencia a la construcción, y no
estar más en el piquete, en el corte de ruta, a pedir
las cosas básicas. Parar de sobrevivir y luchar por
otra cosa: el trabajo digno, la salud, la educación ${ }^{6}$
(Movimiento Evita).

La militancia en el Movimiento Evita procuró construir puentes entre el Estado y los sectores populares que permitieran prolongar la acción pública hacia las poblaciones que necesitaban ayuda social. En el momento del lanzamiento oficial del movimiento, el 9 de mayo de 2006 en el Luna Park, los discursos insistían sobre la necesidad de una mediación de las organizaciones sociales para cumplir los objetivos de inclusión que perseguían las políticas públicas. ${ }^{7}$ El leitmotiv del Movimiento Evita, "No hay proyecto nacional sin movimiento nacional”, evoca, de igual manera, la alianza necesaria entre las organizaciones sociales y el Estado. Esta alianza se viabilizó a través de la incorporación de líderes sociales en las administraciones provinciales y nacionales, como es el caso de Emilio Pérsico, que fue nombrado subsecretario del gabinete del gobernador de la provincia de Buenos Aires

${ }^{6}$ Entrevista con la referente local del Movimiento Evita. ${ }^{7}$ Pagina 12 y La Nación, 10 de mayo de 2006. 
y de otros cuadros del Movimiento Evita que fueron electos diputados en las legislaturas provinciales o en el Congreso nacional. El sentimiento de pertenencia a una misma fuerza política que une las organizaciones territoriales a la cima del Estado está también presente en los relatos de los militantes locales que ponen de relieve la gestión de las cooperativas del programa "Ingreso social con Trabajo" para demostrar su participación efectiva en el poder.

El gobierno ha dado mucho a las organizaciones sociales como la nuestra... organizaciones políticas actualmente... somos parte, de una cierta manera, del Estado. Tenemos cooperativas. (Movimiento Evita).

\section{LA MEDIACIÓN DE LAS ORGANI- ZACIONES POPULARES EN LAS POLÍTICAS SOCIALES}

\section{Nuevas conflictividades y especialización del Movimiento Evita}

La relación orgánica entre el Movimiento Evita y el gobierno nacional se fue reforzando luego del fuerte conflicto del campo en 2008. Durante los cuatro meses de crisis en torno al proyecto de la ley 125 , cuyo objetivo era generar un fondo de redistribución social a partir de un aumento de los impuestos a las exportaciones de la soja, los grupos agropecuarios movilizaron un amplio espectro de actores, desde los grandes propietarios de la Sociedad rural hasta los pequeños productores de la Federación agraria, y recibieron el apoyo de las clases medias porteñas y del interior, a pesar de los múltiples cortes de ruta. Más allá del fracaso del proyecto de ley de Cristina Kirchner, esta crisis puso a la luz la incapacidad de las organizaciones kirchneristas para generar movilizaciones masivas de apoyo al gobierno. El Movimiento Evita con otras organizaciones y con el apoyo del gobierno participó en la creación de la Corriente Nacional de la militancia para paliar esta carencia. Esta preocu- pación fue un caldo de cultivo para generar nuevas prácticas que permitieran movilizar a los actores en torno de un objetivo común.

En este contexto de reorganización de la movilización kirchnerista, la dirección nacional de la organización decidió focalizar su acción hacia el problema del trabajo y los sectores más vulnerables, ya que confiaban en su rol integrador. Esta especialización del Movimiento Evita se concretizó particularmente en su participación en la elaboración y puesta en marcha de políticas públicas que apuntaron al desarrollo de una economía social (Natalucci, 2012). En 2009, los militantes del Movimiento Evita ocuparon un rol central en la definición y realización del programa "Ingreso Social con Trabajo", cuyo primer objetivo fue generar 100.000 empleos genuinos a favor de quienes no trabajaban ni recibían algún tipo de subsidio. Según la documentación oficial, los beneficiarios debían cumplir 40 horas de trabajo por semana y percibirían un sueldo mensual bruto de 1500 pesos. ${ }^{8}$ Esta política social se focalizó sobre las poblaciones más alejadas del mercado de trabajo y sobre los territorios más pobres del país, particularmente en las comunas del conurbano bonaerense.

La creación de cooperativas para trabajadores desocupados radicados en barrios carenciados por medio de una política social presenta ciertos puntos de contacto con la experiencia piquetera de los años 90 y 2000 , cuando estas organizaciones gestionaban los subsidios de los planes "Trabajar" y "JJHD" para sus miembros y realizaban trabajos comunitarios en sus barrios. Con el programa "Ingreso social con trabajo", los miembros de las cooperativas trabajaban igualmente en sus barrios o municipios para mejorar el espacio urbano local, tal como veredas, plazas públicas o edificios comunitarios. La diferencia notable entre ambas experiencias es que el nuevo programa proviene de un acuerdo entre

${ }^{8}$ En 2009, el ingreso supera el salario mínimo fijado a 1240 pesos en diciembre de 2008 y 1400 pesos en agosto de 2009. 
el gobierno y los dirigentes sociales afiliados al kirchnerismo, cuando, durante la crisis del 2001, la demanda y gestión de planes sociales se efectuaba de manera conflictiva entre el Estado y una multitud de organizaciones locales.

El desarrollo de una economía social y sus organizaciones desde el Estado y por medio de políticas públicas genera una serie de preguntas en torno a la génesis y la organización de las cooperativas, la elección de los beneficiarios y las posibilidades de perpetuar las cooperativas y los empleos a partir de la actividad económica creada. El análisis de las prácticas locales de los militantes del Movimiento Evita en el territorio estudiado permite distanciarse del relato oficial sobre los alcances de las políticas sociales y esclarecer las distintas relaciones que se establecen entre las organizaciones sociales y el poder político en este marco institucional.

\section{Constitución del Movimiento Evita a nivel local}

El territorio estudiado se ubica en el primer cordón del conurbano hacia el oeste de la ciudad de Buenos Aires. Su población alcanza los 340000 habitantes, con una presencia mayor de las categorías de empleados y obreros que representan el $67 \%$ de la población activa. ${ }^{9}$ ڤิ A pesar de contar con algunos asentamientos ¿ $\mathrm{y}$ otros barrios muy precarios, la ciudad no fue el escenario de grandes movilizaciones piqueteras durante la época de crisis de 2001. El territorio local estuvo estrechamente vinculado al poder municipal, cuyo máximo representante

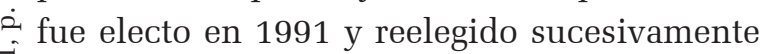
hasta 2015 con porcentajes de votos superiores al 50\%. Este dirigente, que contaba con una larga trayectoria en el Partido Justicialista y la Unión Obrera Metalúrgica, fue uno de los principales aliados del gobernador Eduardo Duhalde durante los años 90 y participó activamente al proceso de territorialización de la política durante esta época (Ollier, 2010). Para

${ }^{9}$ Fuente: Indec, Censo 2010. los militantes locales del Movimiento Evita, el intendente y sus agrupaciones representaban la "vieja clase política corrupta", contra la cual querían diferenciarse. Por eso no prestaban colaboración con el poder municipal, ni con las redes territoriales del peronismo.

De esta forma, el grupo de militante nodal del Movimiento Evita, en este distrito, no provenía ni de una organización piquetera, ni del partido peronista. El reclutamiento primigenio se realizó por fuera de la militancia histórica del peronismo. El mismo se constituyó paulatinamente a partir de 2005, cuando la dirección nacional del Movimiento Evita se puso en contacto con una ex militante de un partido de izquierda para crear una organización en este territorio. Esta militante sigue siendo la referente local y cuenta cómo el grupo se fue armando progresivamente a partir de vínculos militantes y personales.

Cuando empezamos el Movimiento Evita... Primero se conectaron conmigo. Me encontré con una compañera, militamos juntas antes... Empezamos las dos, empezamos a militar y ver lo que se podía hacer en los barrios... nos encontramos con viejos militantes, con otros... y bueno, al final del año, hicimos una juntada con 30 compañeros. No se quedaron todos, no eran todos militantes... Pero bueno, nuestros hijos se agregaron, yo tengo 4 hijos bastante jóvenes que se incorporaron y después sus amigos también vinieron (Movimiento Evita).

Durante cuatro años, se constituyó este núcleo del movimiento a escala local, que tenía actividades esporádicas y había logrado reclutar un número acotado de militantes, vinculados a relaciones interpersonales. Pero la situación cambió radicalmente en 2009 con la puesta en marcha del programa "Ingreso social con trabajo", que atrajo nuevos recursos al territorio. Emilio Pérsico fue el responsable de la conducción de este programa financiado por el Ministerio de Desarrollo Social de la Nación, que derivó la mayor parte de los fondos hacia el Movimiento Evita. ${ }^{10}$ En el ter-

${ }^{10}$ Este fenómeno generó tensiones con otras organizaciones sociales del movimiento kirchnerista. 
ritorio estudiado, la primera versión del programa logró la creación de un total de 25 cooperativas, que contaban con 16 trabajadores cada una. Dentro de este conjunto, 12 estaban gestionadas por los dirigentes del Movimiento Evita. Las restantes dependían de las redes políticas del intendente. En conclusión, las organizaciones territoriales que no estaban en manos del intendente alcanzaban el manejo de 192 subsidios, y competían por lograr una mayor disponibilidad de recursos frente a las redes gestionadas por la comuna. Hacia fines de 2009, el crecimiento de la organización fue exponencial.

La magnitud de los recursos fue en aumento: en 2010, el Movimiento gestionó más de 1000 subsidios a través cooperativas de mayor envergadura, que alcanzaban los 60 trabajadores y, en algunos casos, los 300 trabajadores. La organización se nutrió y densificó. Por ello, produjo distintas jerarquías de adherentes al Movimiento: a nivel local, participaban 30 cuadros militantes que ejercían altas responsabilidades en gestión del Programa, alrededor de 100 simpatizantes comprometidos fuertemente con la organización, que participaban de las movilizaciones del grupo. A estos militantes y simpatizantes se sumaban los miles de trabajadores de las cooperativas a cargo de la organización local del Movimiento Evita.

\section{La elección de los beneficiarios del progra- ma Ingreso Social con Trabajo}

De manera similar a los planes "Trabajar” y "JJHD”, el programa "Ingreso Social con Trabajo" no cubría la totalidad de los beneficiarios potenciales, ${ }^{11}$ lo que imponía una se-

${ }^{11}$ En un archivo de 2012 titulado Rendimos cuentas, el Ministerio de Desarrollo Social de la Nación avanza un numero de 500.000 beneficiarios, pero sin explicitar la elaboración de esta cifra. En esta misma época, análisis mirando la situación socioeconómica desde la perspectiva de la heterogeneidad social subrayaban el crecimiento de un conjunto heterogéneo compuesto por trabajadores precarios, informales, con ingresos bajos, desocupados, subocupados, beneficiarios de planes sociales, sobreocupados con bajos ingresos, que alcanzan en total a la mitad de la población económicamente activa (Kessler, 2014). lección de los demandantes a partir de criterios más o menos explícitos. Por un lado, la ley definía quienes podían recibir esta ayuda: aquellos que no tenían trabajo ni percibían cualquier subsidio. Por otro lado, los militantes agregaban otros criterios propios, en sintonía con las estrategias locales y nacionales del Movimiento Evita, como, por ejemplo, privilegiar en el proceso selectivo a los jóvenes que tenían por lo menos dos hijos. Los militantes repartían también los cupos de manera tal que cubrieran todas las zonas populares del municipio. La selección de los beneficiarios se realizaba a través de relaciones personales de los militantes, que actuaban principalmente en sus propios barrios con la legitimidad del conocimiento íntimo del vecindario;

Nos coordinamos con nuestros compañeros de cada
barrio, que son los que eligen aquellos que vamos a
anotar. Nosotros hemos dividido el número de cu-
pos por barrio. Lo que hacemos es discutir un cri-
terio: primero que el no tenga trabajo... Después el
que tenga más hijos... Prioridad tienen los jóvenes...
Todo este tipo de cosas. Entonces discutimos un
criterio y después cada compañero, en su barrio,
conoce a los vecinos y sabe la ansiedad que tienen.
Por ejemplo, en el barrio de Joaquín, es él que va
a saber a quién tiene que anotar. Otro compañero
va a saber a quien anotar en su barrio y los otros
también. Entonces el criterio que usamos es repartir
el poder y que los vecinos tengan el poder de decir:
'tengo 30 cupos, yo sé a quién les voy a proponer'.
El compañero del barrio dice también: 'este puede
ser presidente, este puede ser capataz... este coordi-
nador' (Movimiento Evita)

Las informaciones anteriores muestran que los militantes del Movimiento Evita, en tanto mediadores de políticas sociales, disponían de un poder discrecional que se asemejaba a las situaciones vividas bajo los gobiernos de Carlos Menem, Fernando de la Rúa y Eduardo Duhalde. Al igual que los planes "Trabajar" y "JJHD", los subsidios del programa "Ingreso Social con Trabajo" son facultativos, condicionados a contraprestaciones, como el trabajo comunitario, y focalizados sobre poblaciones y territorios particulares. Los discursos de los 
militantes, en sintonía con el relato oficial, insistían sobre la creación de "empleos genuinos" y el sentimiento de dignidad que se iba recuperando gracias al trabajo en las cooperativas, pero la naturaleza de las obras realizadas y la escasez financiera del subsidio contrastan con el énfasis del discurso sobre la dimensión laboral. Este programa puso a luz una cierta continuidad de las políticas de lucha contra el desempleo y la pobreza entre los gobiernos Kirchner y los anteriores, dado que los mediadores sociales o políticos seguían gozando de un poder discrecional para distribuir ayudas condicionadas y que los principios de justicia para elegir a los beneficiarios se definían localmente, sin referencia a derechos sociales universales.

\section{Adaptación local del dispositivo y uso de las cooperativas}

La relativa informalidad en torno al uso de los recursos del programa "Ingreso Social con trabajo" dejaba un alto margen de maniobra a los individuos para adaptar el dispositivo a las situaciones concretas que enfrentaban. Los militantes podían redefinir las reglas y los objetivos del dispositivo a partir de su práctica de mediación, a fin de resolver los prob: ì lemas de los beneficiarios. En esta perspectiva, Фं los responsables locales del Movimiento Evita no gestionaban las cooperativas focalizándose en los objetivos de la actividad y producción económica, sino que las consideraban como espacios de socialización que permitían a trabajadores desocupados de iniciar o prolongar un proceso de inserción profesional. De este modo, la etnografía sobre este territorio exhibe que la organización modificó el criterio de la desocupación y la reglamentación del horario laboral para que los beneficiarios pudieran ener otro trabajo y acumular los sueldos:

El ingreso es de 1340 pesos... y eso no es suficiente. iNecesitamos el triple! Pero trabajan seis horas...

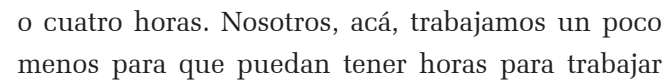

La modificación de las reglas del dispositivo a partir de las prácticas de mediación puede ser vista también como una forma de experimentación cuyo resultado puede cambiar el marco institucional. La estrecha alianza entre el Movimiento Evita y el gobierno nacional permite prever que existía un estrecho diálogo entre los actores que definían las políticas sociales y aquellos que las implementaban en los territorios. La misma adaptación de los horarios laborales, que existía desde 2009 en el distrito estudiado, se institucionalizó a partir de 2012 con un cambio de las remuneraciones y condicionalidades. Se agregó, además, una serie de incentivos: al ingreso básico se adicionaban mensualmente retribuciones de 300 pesos por una alta productividad, y de 250 pesos por una presencia regular en puestos de trabajo. $\mathrm{Si}$ bien los criterios en torno de una alta productividad no eran explícitos para otorgar la prima, los de la presencia regular se establecían en la cumplimentación de cuatro horas diarias, es decir, una medida que ya estaba en vigencia en las cooperativas analizadas. Según la presidenta de la Nación, Cristina Kirchner, este mejoramiento en los subsidios se concibe como una recompensa para los trabajadores más meritorios. ${ }^{12} \mathrm{Al}$ acumular el subsidio de base con las primas de productividad y de presencia, un beneficiario de esta política social percibía alrededor de 2000 pesos netos mensuales, es decir, el equivalente de un salario mínimo en 2012, por una contraparte de cuatro horas de trabajo por día.

\footnotetext{
${ }^{12}$ Ver el artículo titulado "Mejoras en los planes Argentina Trabaja" en el diario La Nación publicado el 29 de febrero del 2012.
} 


\section{LAS COOPERATIVAS COMO RE- CURSOS DE UNA RED DE MILI- TANCIA}

\section{Constitución de Una Red Territorial}

La relación entre el Movimiento Evita y el gobierno nacional no se resume tan solo en la puesta en marcha de políticas sociales. Como lo señalamos en la primera parte, la crisis del campo puso al descubierto una falla del kirchnerismo en cuanto a las movilizaciones masivas y provocó la creación de una Corriente Nacional de la Militancia, de la cual participó el Movimiento Evita. En el territorio estudiado, esta voluntad de fomentar la militancia en los barrios populares a fin de ampliar la capacidad de movilización se manifestó a través las múltiples actividades que generaron los militantes en torno a las cooperativas.

Para reclutar los responsables de cada cooperativa, ${ }^{13}$ los dirigentes locales del Movimiento Evita escogieron a los candidatos que se comprometían para militar en los barrios y realizar actividades comunitarias, adicionando nuevos criterios a los ya descriptos en el apartado anterior. De este modo, la organización pudo movilizar ampliamente a los habitantes e instalar comedores, centros de jubilados, centros culturales, clubes deportivos, murgas, puestos sanitarios, talleres de alfabetización, etc. Como muchas redes sociopolíticas, los militantes aseguraron también la distribución de productos alimentarios de base a las familias más desfavorecidas. En 2010, la organización afinó su perfil asociado a la política y hubo una especialización en torno a la actividad a partir de una división del trabajo político: la treintena de personas que ocupaban cargos de responsabilidad al interior de la organización se reunían una vez por semana para coordinar las múltiples tareas. Dentro de

${ }^{13}$ Les cooperativas tienen su propia personería jurídica y están inscriptas en el Registro nacional de las organizaciones de la sociedad civil. Los estatutos deben precisar como información mínima los apellidos del presidente y secretario de la organización. Las obras realizadas por las cooperativas son dirigidas por un capataz. este conjunto, grupos de tres a cinco personas tenían a cargo tareas específicas, tales como: la coordinación de la relación entre las cooperativas y el Movimiento Evita; la vinculación con las instituciones públicas, especialmente el municipio; la búsqueda de financiamientos públicos para tareas comunitarias (provincia, Nación, PNUD, etc.); el desarrollo de actividades asociativas en las áreas de salud, educación, vejez, cultura, deporte, etc. Este núcleo, que describía un compromiso elevado con la organización, planificaba una reunión mensual, con el objeto de reagrupar a los simpatizantes que militaban en los barrios populares y se identificaban con el Movimiento Evita, la cual reunía un centenar de personas.

Con el fin de paliar el descrédito que sufría la actividad política e incitar a los jóvenes de la comuna a participar en las tareas comunitarias, los militantes creaban, de igual manera, asociaciones civiles cuyos objetivos explícitos se limitaban a acciones concretas que se llevan adelante. Así, cuatro jóvenes militantes fundaron la asociación civil Colectivo Popular para la Liberación, con el objeto de generar un espacio de participación por fuera del Movimiento Evita, es decir, sin etiquetas políticas. Esta asociación les permitió movilizar otros jóvenes de la comuna, generalmente provenientes de clases medias, para los talleres de alfabetización y las animaciones culturales. La creación de estas asociaciones civiles fue un vehículo para movilizar jóvenes desvinculados de la política, iniciando un proceso de politización a través del cual pudieron transformar su participación asociativa puntual en un compromiso militante, en sintonía con el Movimiento Evita. Un extracto de entrevista permite observar este tipo de movilización asociada a una "política de juventud":

Empezamos a convocar a los jóvenes por cadenas de mails, a través de blogs, páginas de Internet, por la radio... Preguntamos quién quería ser voluntario para la alfabetización. Y eso, no lo hicimos desde el Movimiento Evita porque... El Movimiento Evita es un movimiento peronista y aquí, para muchos, 
el peronismo está ligado a la vieja política, a la corrupción. Entonces, nos dijimos: 'construyamos un espacio para los jóvenes que no quieran identificarse con el Movimiento Evita, pero que quieran solamente hacer una actividad solidaria'. Así, hay muchos jóvenes que vinieron, como 30,40 ! De golpe hay 30 y 40 que aparecieron en ese barrio donde nadie quiere entrar... Y muchos se acercaron después al movimiento [Evita], muchos de esos jóvenes (Movimiento Evita).

\section{Movilizaciones de apoyo al gobierno nacional}

La gestión de las cooperativas y el trabajo militante en los barrios permitieron que la organización local del Movimiento Evita construyera una red territorial a fin de movilizar centenas de vecinos para distintos actos políticos. Algunos actos estaban asociados a momentos propios de la liturgia peronista, como la celebración del día de la lealtad, ${ }^{14}$ o la conmemoración de la muerte de Eva Perón (Plotkin, 2012). Otros estaban vinculados a la política nacional, y los simpatizantes eran convocados para manifestaciones de apoyo al gobierno en momentos de confrontación con la oposición, como fue el caso, en 2009, con la ley de matrimonio igualitario, que reconoce el derecho a matrimonio entre personas del mismo sexo, y la ^ ley de medios, que apuntaba a limitar los mo亏ิ nopolios en el sector mediático. La valoración ه de estas movilizaciones era doble. Primero, i eran testimonios de la adhesión al proyecto $\infty$ político y lealtad a los lideres Néstor y Cristina Kirchner. Segundo, eran demostraciones de is su capacidad a movilizar masivamente a favor i del gobierno. La referente local relata cómo incitaba a los "compañeros" a participar en esas movilizaciones y en qué medida el número de participantes era importante para negociar más cupos con las dirigencias nacionales:

Cuando hay marchas... Puede ser por muchas ra-

${ }^{14}$ El día de la lealtad peronista conmemora, cada 17 de octubre, la movilización popular del año 1945 que exigió la liberación de Juan Domingo Perón y selló la íntima relación entre el peronismo y las clases populares. zones, una movilización por el aniversario de la muerte de Evita o para apoyar al gobierno porque le esta presionando mucho la derecha... Para todo, nosotros apoyamos. Entonces decimos: 'Compañeros, nosotros vamos el martes a hacer esta marcha, ¿quién quiere venir? El que quiere venir, tiene el día libre. El que no, va a trabajar'. Y listo, no hay una presión, porqué antes se decía mucho acá que al que iba se lo pagaba, en el micro. [...] Pero decimos también: "si vamos a hacer una marcha por la conmemoración de la muerte de Evita, y en vez de ser 30 de Tres de Febrero somos 300, Tres de Febrero va a tener otra consideración al momento de plantearse: ‘¿bueno a quien le damos cupos de trabajo?’. Bueno, entonces, no hay una presión efectiva, del tipo 'yo no te pago si no venís'. Yo doy esa explicación a los compañeros y eso hace que, muchas veces, se va tomando conciencia. Antes movilizábamos un micro y ahí, por ejemplo, para la última marcha, ifuimos con 14 micros! i14 micros! Para nosotros, es un gran crecimiento (Movimiento Evita)

No obstante, además de estas "utilidades” explícitas, las movilizaciones tenían un valor simbólico muy elevado: eran momentos de politización que permitían a los participantes de apropiarse, compartir y renovar culturas e identidades políticas.

\section{Inscripción en el juego político local}

Esta capacidad de movilización de los habitantes de barrios populares jugó un rol importante en las relaciones de fuerza con los intendentes del conurbano de Buenos Aires. En 2009, luego de la derrota de Néstor Kirchner y el Frente para la Victoria en las elecciones legislativas, la candidatura a presidente de Néstor Kirchner quedó indefinida, y Eduardo Duhalde representaba, entonces, un competidor serio en la interna del peronismo. En vistas de esa posible disputa y sabiendo que el intendente del territorio estudiado era un aliado de Duhalde, los militantes locales del Movimiento Evita participaron de una plataforma política agrupando a otras organizaciones peronistas (La Cámpora, Peronismo militante, Descamisados) y corrientes del Partido comunista y del 
Partido socialista bajo la óptica de montar una lista electoral local y liderar la campaña de Kirchner en el territorio:

La idea de esta plataforma política es la de formar un espacio en el territorio, de fortificar un espacio que pueda el día de mañana entrar en competencia electoral con los sectores que hay acá... que son más bien de derecha y que están en el poder hace 20 años. Lo que pasa es que si Kirchner decide jugar con el Partido Justicialista, con los intendentes del conurbano, lo vamos a apoyar. Si hay lugares donde podemos pelear por un mejor candidato, vamos a pelear. Todo depende de cómo será la situación y es diferente para cada territorio (Movimiento Evita)

Las tensiones entre el intendente y los militantes del Movimiento Evita fueron recurrentes desde la puesta en marcha del programa "Ingreso social con trabajo". Esta situación conflictiva se hizo aun más presente, ya que es la municipalidad la que pagaba los sueldos de las cooperativas y proveía las herramientas $\mathrm{y}$ vestimentas de trabajo. Los militantes cuestionaban el funcionamiento de los servicios administrativos y los bloqueos provocados por los dirigentes municipales para ralentizar la actividad de las cooperativas. Con el fin de solucionar estos "obstáculos burocráticos", la coordinación nacional del Movimiento Evita creó, en 2010, la federación de cooperativas Todos Unidos, que vinculaba, de forma directa y sin mediación municipal, las organizaciones de más de 300 trabajadores con los ministerios de desarrollo social de la Nación y de la provincia de Buenos Aires.

En consecuencia, a través de las organizaciones sociales kirchneristas, tales como el Movimiento Evita, el gobierno nacional intervino directamente en los territorios del país sin pasar por las distintas escalas del Estado. La militancia que reclutaban estas organizaciones en los barrios populares permitía igualmente al gobierno nacional de competir con las redes territoriales de los intendentes, particularmente aquellos del conurbano bonaerense.

\section{CONCLUSIÓN}

Las relaciones entre las organizaciones territoriales y el Estado se modificaron sustancialmente con la asunción de Néstor Kirchner a la presidencia de la Nación. Fue a partir de ese momento que se inició un proceso que confluyó en una estrecha alianza entre el gobierno nacional y las organizaciones sociales: aquellas que encontraron un eco favorable a su llamado conformaron el espacio militante kirchnerista. El rol de estas organizaciones sociales bajo el mandato de Néstor Kirchner se conformó, principalmente, a partir de la mediación de políticas sociales focalizadas en territorios y poblaciones de alta vulnerabilidad. El Movimiento Evita se constituyó en este contexto y concentró su acción en el conurbano bonaerense a favor de los sectores más pobres.

Luego de la crisis del campo en 2008, que debilitó el gobierno de Cristina Kirchner, se operó una reorganización de la movilización kirchnerista de la cual participó de forma muy activa el Movimiento Evita. El análisis de las actividades de una organización local en el marco del programa "Ingreso social con trabajo" ilustra la variedad de prácticas que realizaron los mediadores y beneficiarios a nivel local. Por un lado, los militantes reclutaban vecinos de barrios carenciados para conformar las cooperativas y distribuir los subsidios. Por otro lado, desarrollaban actividades comunitarias en los barrios y constituyeron redes de militancia que les permitían movilizar los habitantes para actos políticos.

A pesar del relato oficial sobre la dignidad del trabajo y la creación de empleo genuino, el tipo de actividades y la escasez del ingreso asemejan esta política social a los planes "Trabajar" y "JJHD", puestos en marcha durante el periodo neoliberal. El programa "Ingreso social con trabajo" se inscribe en el modelo de políticas de transferencias condicionadas de ingreso, muy difundido en América Latina durante los años 1990 y 2000. La referencia a los valores de la economía social y el cooperativis- 
mo, en los discursos militantes, se concretizó escasamente en las prácticas de los actores, ya que las organizaciones sociales vinculadas con el Movimiento Evita revestían una escasa autonomía, tanto frente a la dimensión operativa ofrecida por el municipio como por la dependencia de las disposiciones y financiamiento del gobierno nacional. La mediación efectuada por los militantes demostró una adaptación del dispositivo, que transformó las cooperativas en espacios transitorios de socialización e inserción laboral.

Otra continuidad con el periodo anterior se observa en cuanto al modo de transferencia de los subsidios. El número de cupos del programa fue muy inferior al número de los posibles beneficiarios, lo que impuso una selección de los candidatos a partir de criterios definidos en parte por la ley, en parte por los mediadores. El poder discrecional de los mediadores, hayan sido militantes sociales o políticos, pone en cuestión el régimen de acción pública. Sin referencia a un derecho social universal, la transferencia de subsidios se inscribió en el marco de un régimen de favores con el riesgo de fomentar relaciones de dependencia. A partir de esta modalidad de trasferencia, se plantea una diferencia marcada con otra política social planificada en ese mismo momento, la "Asignación Universal por Hijo", ثิ \ y el ciudadano, y cuyo presupuesto se asigna en su totalidad a los beneficiarios sujetos a un criterio de base.

Las redes de militancia que el Movimiento Evita conformó, en los territorios populares, a partir de los recursos del programa "Ingreso social con trabajo", ilustran la permanencia के de imbricaciones entre los lazos asociativos y

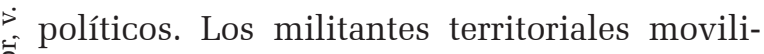
zan a los habitantes para apoyar el proyecto encarnado por Néstor y Cristina Kirchner. No obstante, el rol de las organizaciones populares territoriales y su legitimidad, en el periodo kirchnerista, contrastan fuertemente con la década anterior. La reactivación de la tradición nacional-popular y el movimentismo han consolidado los vínculos entre la cúpula del Estado y las organizaciones sociales, y han generado circuitos alternativos a las distintas administraciones estatales descentralizadas. Estas redes sociopolíticas permitieron al gobierno nacional intervenir directamente en los territorios populares a través de políticas sociales focalizadas e influir sobre la vida política local, generando una competencia política entre los dirigentes de distintas escalas estatales. Finalmente, el caso del Movimiento Evita y el programa "Ingreso social con trabajo" pone de relieve el rol central de las organizaciones populares en el diseño y la puesta en marcha de las políticas de inclusión durante los gobiernos kirchneristas, aunque el predominio de una lógica partidaria en las relaciones entre el Estado y las organizaciones sociales parece favorecer la construcción de poder a nivel central y no la autonomización del espacio asociativo a nivel local.

Recebido para publicação em 10 de maio de 2016 Aceito em 11 de setembro de 2017

\section{REFERENCIAS}

AUYERO, J. La política de los pobres: las prácticas clientelitas del Peronismo. Buenos Aires: Manantial, 2001.

BRODIEZ-DOLINO, A. Combattre la pauvreté. Paris: CNRS Éditions, 2013.

CASTEL, R. Les métamorphoses de la question sociale. Paris: Gallimard, 1995.

CEBALLOS, M.; LAUTIER, B. Les CCTP en Amérique Latine. Entre modélisation internationale et conjonctures politiques nationales, Revue Tiers Monde, Paris, v. 214, n. 2, p. 219-245, 2013.

CORAGGIO, J. L. La présence de l'économie sociale et solidaire et son institutionnalisation en Amérique Latine. États généraux de l’ESS, Paris, 17 al 19 jun. 2011.

CORTÉS, R.; KESSLER, G. Políticas, ideas y expertos en la cuestión social de la Argentina democrática (19832012). Revista de Indias, Huelva, n. ${ }^{\circ} 257$, p. 239264, 2013.

DELAMATA, G.; ARMESTO, M. Construyendo pluralismo territorial. Las organizaciones de desocupados del Gran Buenos Aires en la perspectiva de sus bases sociales. En: DELAMATA, G. Ciudadanía y Territorio: Las relaciones políticas de las nuevas identidades sociales. Buenos Aires: Espacio, 2005. p. 105-155.

ESPING-ANDERSEN, G. The Three Worlds of Welfare 
Capitalism. Princeton: Princeton University Press, 1990.

FALAPPA, F.; ANDRENACCI, L. La política social de la Argentina democrática (1983-2008). Los Polvorines: UNGS, 2008.

KAMERMAN, S. The new mixed economy of Welfare: Public and private, Social work, [S.l.], v. 28, n. 1, p. 5-10, 1983.

KESSLER, G. Las consecuencias de la estigmatización territorial. Reflexiones a partir de un caso paradigmático. Espacios en blanco, [Buenos Aires] v. 22, n. 1, p. 165-198, 2012

KESSLER, G. Controversias sobre la desigualdad: Argentina 2003-2013. Buenos Aires: Fondo de cultura económica, 2014.

KESSLER, G.; SVAMPA, M.; GONZÁLEZ BOMBAL, I. Reconfiguraciones del mundo popular: El Conurbano Bonaerense en la postconvertibilidad. Buenos Aires: Prometeo, 2010.

LAUTIER, B. Gouvernement moral des pauvres et dépolitisation des politiques publiques en Amérique latine. Tiers monde, Paris, n. 214, p. 169-186, 2013.

LEVITSKY, S. La transformación del justicialismo: Del partido sindical al partido clientelista, 1983-1999. Buenos Aires, Siglo XXI, 2005.

LO VUOLO, R. El Programa Argentina Trabaja y el modo estático de regulación de la cuestión social en el país. Documentos del CIEPP, Buenos Aires, n. 76, p. 1-20, 2010.

LODOLA, G. Protesta popular y redes clientelares en la Argentina: el reparto federal del plan trabajar (1996-2001). Desarrollo Económico, Buenos Aires, v. 44, n. 176, p. 515536, 2005

MERKLEN, D. Une nouvelle politicité pour les classes populaires: Les piqueteros en Argentine, Tumultes, Paris, n. 27, p. 173-197, 2006.

MERKLEN, D. Quartiers populaires, quartiers politiques. Paris: La Dispute, 2009.

MERRIEN, F. X. Réformer et étendre les régimes de protection sociale des pays émergents d'Amérique latine : entre héritage institutionnel et réception d'idées. Revue française des affaires sociales, Paris, n. 3, p. 14-29, 2014.

MURILLO, M. V. Sindicatos, coaliciones partidarias y reformas de mercado en América Latina. Buenos Aires: Siglo XXI, 2005.

NATALUCCI, A. Los movimentistas. Expectativas y desafíos del Movimiento Evita en el espacio kirchnerista (2003-2010). En: PEREZ, G.; NATALUCCI, A. Vamos las bandas: Organizaciones y militancia kirchnerista. Buenos Aires: Trilce, 2012. p. 27-53.

OLLIER, M. M. Atrapada sin salida: Buenos Aires en la política nacional, 1916-2007. San Martin: UNSAM Edita, 2010.

PEREZ G., NATALUCCI A. Vamos las bandas: Organizaciones y militancia kirchnerista. Buenos Aires: Trilce, 2012.
PLOTKIN, M. El día que se inventó el peronismo: La construcción del 17 de octubre. Buenos Aires: Sudamerica, 2012

PRÈVÔT-SCHAPIRA, M. F. Las políticas de lucha contra la pobreza en la periferia de Buenos Aires, 1984-1994. Revista Mexicana de Sociología, Mexico, v. 58, n. 2, p. 7394, 1996.

QUIRÒS, J. El porqué de los que van. Buenos Aires: Antropofagia, 2011.

RODRÍGUEZ ENRÍQUEZ, C.; REYES, M. F. La política social en la Argentina post-convertibilidad: políticas asistenciales como respuesta a los problemas de empleo. Documentos del CIEPP, Buenos Aires, n. 55, p. 1-73, 2006.

ROITTER, M. GONZÁLEZ BOMBAL, I. Estudios sobre el sector sin fines de lucro en Argentina. Buenos Aires: Centro de Estudios de Estado y Sociedad, 2000.

ROSANVALLON, P. Le modèle politique français: La société civile contre le jacobinisme de 1789 à nos jours. Paris, Seuil, 2004.

SCHUSTER, F. et al. Tomar la palabra: estudios sobre protesta social y acción colectiva. Buenos Aires: Prometeo, 2006

SVAMPA M. Cambio de época: movimientos sociales y poder político. Buenos Aires: Siglo XXI, 2008.

SVAMPA, M.; PEREYRA, S. Entre la ruta y el barrio: La experiencia de las organizaciones piqueteras. Buenos Aires: Biblos, 2003.

SVAMPA, M.; PEREYRA, S. La política de los movimientos piqueteros. En: . SCHUSTER F. et al. Tomar la palabra: Estudios sobre protesta social y acción colectiva. Buenos Aires, Prometeo, 2006. p. 343-364

THOMPSON, A. Políticas públicas y sociedad civil en Argentina. Documentos del CEDES, Buenos Aires, n. 113, p. 1-64, 1995

VOMMARO, G. Política popular en tiempos de economías postindustriales: trabajo territorial y economía moral en la Argentina reciente. Revista Pós Ciências Sociais, São Luís, v. 14, p. 77-98, 2017.

VOMMARO, G. COMBES, H. El clientelismo Político, desde 1950 hasta nuestros días. Buenos Aires: Siglo XXI, 2016.

WILLIAMSON, J. What Washington means by policy reform. En WILLIAMSON, J. Latin. American adjustment: How much has happened? Washington: Institute for International Economics, 1990

ZARAZAGA, R. Política y necesidad en Programas de Transferencias Condicionadas: la Asignación Universa por Hijo y el Programa de Inclusión Social con Trabajo Argentina Trabaja. En: ACUÑA, C. El Estado en acción. Buenos Aires: Siglo XXI, 2014. p. 71-107. 


\section{SOCIAL POLICIES AND POPULAR ORGANIZATIONS IN ARGENTINA (2003-2011): social mediation and political mobilization in the suburbs of Buenos Aires}

Arnaud Trenta

Incorporated in the debates about ruptures and continuities between Argentine governments of the last decades, the article analyzes the social policies focused on the fight against poverty. The paper examines in particular the relationship between the State and grassroots organizations during first Kirchnerist governments (2003-2011) and the implementation of a social inclusion program called "Social Income with Labor", which aims to create worker cooperatives in high-poverty neighborhoods. On one hand, the results show a continuity of social policies design and implementation during the 1990s and 2000s through the model of conditional cash transfers programs, that grant a discretionary power to the brokers. On the other hand, the research illuminates the reconfiguration of working class relations with the State through the political alliance between the national government and grassroots organizations. The methodology is based on interviews and observations of a local organization of the Evita Movement that manages numerous cooperatives of the program "Social Income with Work" in a district of Buenos Aires suburb.

Keywords: Social Policies. Grassroots Organizations. Working Class. Kirchnerism; Argentina.

\author{
POLITIQUES SOCIALES ET ORGANISATIONS \\ POPULAIRES EN ARGENTINE (2003-2011): \\ médiation sociale et mobilisation politique dans \\ les quartiers périphériques de Buenos Aires
}

\author{
Arnaud Trenta
}

L'article s'inscrit dans les débats sur les ruptures et continuités des politiques gouvernementales en Argentine au cours des dernières décennies, à partir de l'analyse des politiques de lutte contre la pauvreté. La recherche examine particulièrement les relations entre l'État et les organisations associatives durant les deux premiers gouvernements kirchnéristes (2003-2011) et se focalise sur la mise en œuvre de la politique d'inclusion sociale dénommée "Revenu social par le travail", qui vise la création de coopératives de production dans les quartiers paupérisés. Les résultats de la recherche empirique démontrent une certaine continuité du design et de l'implémentation des politiques sociales entre les années 1990 et 2000, à travers le modèle des programmes de transferts monétaires conditionnels. La recherche montre également une reconfiguration des rapports au politique des clases populaires qui se manifeste par l'alliance des organisations territoriales avec le gouvernement national. La méthodologie repose sur la réalisation d'entretiens et d'observations auprès d'une organisation locale du Mouvement Evita qui gère de nombreuses coopératives du programme "Revenu social par le travail" dans une ville de la banlieue de Buenos Aires.

Mots-CLÉs: Politiques sociales. Associations. Classes populaires. Kirchnerisme. Argentine. metodología de trabajo combina la comparación internacional, el análisis multiescalar y la observación etnográfica. Es becario postdoctoral del Consejo Nacional de Investigaciones Científicas y Técnicas (CONICET), con lugar de trabajo en el Instituto de Ciencias Humanas, Sociales y Ambientales (INCIHUSACCT) de Mendoza, Argentina. Entre sus publicaciones, mencionamos: la coordinación, junto con Camille Hamidi, de "Associations et classes populaires : quels rapports au politique ?”, Sociétés contemporaines, en prensa; "Les pratiques associatives dans les banlieues de Paris et Buenos Aires. La comparaison de cas contrastés », Espaces et sociétés 2015/4 (n 163), pp. 41-55 ; y, junto con Leandro Sebastían Lopez, "La citoyenneté ordinaire dans les quartiers de Buenos Aires”, Revue Tiers Monde, n.. 216, pp. 179-196, 2014. 